ARTICLE

Received 3 Mar 2017 | Accepted 18 May 2017 | Published 4 Jul 2017

DOI: $10.1057 /$ palcomms.2017.57

OPEN

\title{
The interiorscape: amalgams and composites
}

\author{
Graeme Brooker $^{1}$
}

\begin{abstract}
This essay will explore the implications of the reuse of existing buildings with which to make new interior space. It will advance the idea of the interiorscape: a fluid and dynamic landscape created by a series of particular activities, produced by agents in the field. I suggest that the interiorscape can be considered to be a spatial amalgam: a composite construct of historical, cultural and spatial formations. Interiorscapes are environments that are often devised for the realization of particular spatial identities for various forms of inhabitation, and are the result of a composite compound of both new and old material. In order to fully comprehend the interiorscape, this essay designates methods of reuse as progressions of integrative activities. These are processes that select, edit, reform, transform, and recontextualise existing objects, spaces and buildings. For clarity, Hegewald's and Mitra's description of reuse is employed. Based on their understanding of integrative processes, advancing the Interiorscape through the lens of reuse, leads to the origination and construction of what will be described as spaces that can be considered to be amalgams and composites. These are environments that, because they are constructed from many different elements, originated from numerous diverse timescales, they are what we term compounds: combinations of several distinctive physical and immaterial entities. All of which are amalgamated together, to forge new spatial meanings. This is the fundamental principle of the interiorscape. To conclude this essay, a critical underpinning of the interiorscape with the processes of reuse is drawn together, using various spatial exemplars with which to typify how scapes and amalgamated matter, produce unique compositely constructed interior environments. Entities, it is concluded, contain the fundamental principles of the conditions of interior space. This article is published as part of a collection on interiority.
\end{abstract}

\footnotetext{
${ }^{1}$ Royal College of Art, Interior Design, London, UK
} 
T his essay will explore the implications of the reuse of existing buildings with which to make new interior space. This investigation is based on the assumption that the creation of interior space is virtually always as a product of the working with, and the alteration of, existing environments. Whether the line on a page or a screen, or whether working with an existing building, the architectured, designed and decorated interior environment is always the result of working with the extant. As Adams stated in Toward a Theory of Interior;

"Architecture serves only as an armature for interior-a scaffolding on which interior quietly restructures its world" (Adams 2017).

Therefore, the making of the interior, its conception and its production, as well as its fabrication, can be construed as a set off processes resulting in an environment that is not necessarily reliant on the architectural envelope in which it resides.

To advance these ideas, I will detail two domestic spaces, both of which have been created through the transformation of extant constructions. In choosing these two spaces, I will propose that an interiorscape is the result of the amalgamation of both new and old elements: a process that results in the creation of a new composite construct of interior space. This is undertaken in order to offer a site specific, context-driven response to aspects of the contemporary conditions of the built environment. These are situations that explicate the construction of locality, processes that, by using the work of Appadurai (1996) will be outlined in the conclusion to this essay.

In essence, I will propose that the interiorscape can be considered to be the result of a spatial amalgam: a composite construct of both historical and contemporary matter. Interiorscapes are environments that are often realised through a range of activities, and devised for the realization of particular sitespecific environments. They are spaces that can contain the essences of the production of various localities, qualities that are evident in their social immediacy, interactivity, and their contextual and site based attributes.

In order to make explicit the connections between reuse and the conception and production of interior environments, this essay explores reuse and how, through the use of particular recombination strategies, matter can be analysed and repurposed to create meaningful and distinct inside spaces. It will propose that the processes of reuse are intrinsic to the formation of the interior, and hence are central to the construction of its scape: an environment that is both, simultaneously, tangible and immaterial, and one that is always located in a specific place: a place not necessarily determined by the architectural environment in which it is situated.

To assist with a deeper comprehension of the interiorscape, this essay designates methods of reuse as iterative site-specific progressions of integrative activities. This means that they are processes that are predicated on repeated context-based procedures that select, edit, reform, transform, and recontextualise existing objects, spaces and buildings. For clarity, I will utilize Hegewald's and Mitra's description of reuse.

"Reuse essentially refers to using an item again. This can be an object, an edifice, building materials, a style, a law, a concept, a form of governance, an idea or anything else. It is a deliberate and selective process in which existing elements are borrowed and taken out of their former surroundings to be applied to a fresh context. For this to happen, a disruption and a break have to happen, favouring confrontation with something new. Re-use does not imitate and replicate; it is a creative combination of old and new elements which aims to take the item or concept further" (Hegewald and Mitra, 2012a)
Based on this understanding, the interiorscape can be understood as a composite construct of reused material, exemplifying continuity and foregrounding legacy. The two distinct domestic spaces that I will discuss exemplify the interiorscape through their site-specific uniqueness. In particular, in each exemplar, an amalgam of particular contextual factors has formed a composite: a spatial configuration that is impossible to recreate in new build architecture. In these two exemplars, not only is the site a place of critical importance for the reuse, but it is also the source of a pervasive uncertainty and volatility. In response to this contextbased unpredictability, I suggest that by making this amalgamated compact, these Interiorscapes are spaces that can be considered to be the site of the production of a very specific locality: a sitespecific development made explicit through its physical, social and contextual properties.

\section{The Interiorscape}

What is the relevance, or even the meaning of the interiorscape? The interiorscape is the site of locality and a context driven sitespecific condition, also known as a place. Firstly, separating the term into its two main components, interior and scape, may help to develop some comprehension. The word "Interior" has gone through many changes in meaning. Inter is derived from the Latin Interrare, to Interre, or to bury (Barnhart 1988a). This fundamental root of the word alludes to a deeper meaning, one where the interior is literally rooted to a very particular and sometimes subterranean place. "Interre" has other connections. It is derived from "Antar", a Sanskrit word that, over time, has evolved to become "enter". This is a familiar word in the language of the interior. It is one that is closely related to a fundamental aspect of the creation of inside space: a boundary between outside and in. In the eighteenth century, Interior becomes more recognizable in the contemporary sense of the word. Here, Interior was used to describe the non-coastal regions of continents, outlining a territory inside a country. It was also often used to describe the inside of a person. Therefore, while it was used to portray the physical aspects of the body interior, it was also used to describe the abstract form of a spiritual human dimension: an inner element or entity that was something other than exterior. It was only in the nineteenth century that the word interior started to be used specifically in order to designate the inside of an environment such as a building. Even then, its use was often limited to the description of domestic space, and in particular it would often be utilized to describe the Victorian bourgeoisie home (Rice 2007). In essence, the root of the term interior embodies a strong site-orientated association. It describes a particular space defined by an enclosure. This is a boundary that delineates, albeit sometimes ambiguously, where the inside is separated from the outside, and when the interior begins and where it ends.

In the Oxford English Dictionary, scape is most often used in affiliation with a variety of external forms of environment (Onions, 1972). Landscapes, seascapes, moonscapes are words that all suggest a strong external presence. Yet they all describe environments with an ambiguous character: a setting yet to be assigned a particular identity or designated a specific use. In the same dictionary, to escape is described as the act of gaining liberty through egress. ${ }^{2}$ In the Etymological dictionary, escape is a thirteenth century term used to describe the act of fleeing by literally leaving nothing behind but your cape, often in the hands of your pursuer (Barnhart, 1988b). The image projected by this description, amusingly illustrates a fundamental aspect of the word scape, one that describes a fleeting moment with a lasting impression left behind. Each description suggests that scape is an ambiguous term. It is a word that only fundamentally resonates, 
with any meaning, when associated with a particular object, landmass, or a space.

When both terms are put together, the Interiorscape becomes an expression that can be used to describe both an ambiguous and distinct spatial condition. It is a space that exists, in that it is demarcated, but it is one that could appear to lack a form or a specific designation. It could be described as a space that has left a fleeting or temporal impression, yet one that could be sitespecific. This affords the interiorscape both a distinct and uncharacteristic aspect and an anomalous dimension. It describes a space that is unusual and inconsistent, and one that is possibly out of the ordinary. The interiorscape is a vessel, a demarcated entity, but one that is undesignated, waiting to be filled with a particular form of occupation.

I propose that the language of the interiorscape denotes meanings that imply a context dependent situation, one where elements and environments, and possibly other scapes, concatenate and amalgamate. I propose that the interiorscape is the place of the production of locality and hence is site-specific. Because of this quality, the interiorscape fosters social immediacy through connecting its occupants to memories, through history, and through context. It constitutes connections and associations between site, people, communities and places.

\section{Reuse}

What gives the interiorscape its distinct qualities in the production of locality? For clarity I am employing the work on reuse by Hegewald and Mitra, and in particular their work in the book Re-Use and the Politics of Integration and Anxiety (Hegewald and Mitra, 2012a). In this publication, along with numerous other authors, they give a very thorough overview of reuse, particularly in the humanities and social sciences. This is in order to make explicit what I consider to be the intrinsic link between people, places, and site, through re-using existing elements, objects and spaces. In particular they explore reuse in the visual and religious, and the social and political aspects of all sorts of objects, environments, and policies. These are ideas and elements that they consider to have been enriched through hybridity, and which have been originated through the conflation of the past and the present. I have employed their work for its clarity in explaining aspects of reuse, because, primarily, the authors explore the transnational flow of ideas, concepts, objects, environments, but as persistent strategies for the use of the past in informing the present. In other words, matter is evidenced as a hybrid or composite form. That is, whether concept, object or environment, it is an amalgam of both old and new. As they state;

"Through the phenomenon of reuse, new elements become available to cultures and favour renewal and innovation" 3

In other words reusing matter, whether concepts, objects or environments, favours, through disruption to the flow of "use", a deep and intrinsic connection to the past, and often to a particular site or a specific context. It is a situation that reinforces connections between people, places and "things".

In their book, the authors set out categories of reuse, ranging from what they call conventional reuse, where they use the example of a milk bottle being emptied and then filled up and used again, and new-life reuse, where a concept, object, element, environment is repurposed for a completely new use to that what it was originally intended for. Other authors in the book (Barnard, 2012) describe variations on this theme, drawing a distinction between artistic and meaningless reuse. Artistic reuse places emphasis on the transformation of matter, deliberately because of what it represents, and the residual meaning of that element becomes an essential part of its new use. In other words, meaningless reuse could be described as recycling elements such as the milk bottle. Whereas artistic reuse values the previous meaning of the matter to be transformed, as it will add something to the new amalgamated element. This approach places emphasis on the connotations of the element to be reused, as well as the close analysis of its properties, in order to influence its transformation. As Hegewald and Mitra (2012b) state;

"During the process of reuse, certain elements and meanings can get lost, and this can create anxiety in those whose objects have been repurposed. However, in the long run, the incorporation of elements from the past in the present, creates a certain continuity, and can actively contribute to integration"

In this context of reuse, the issue of integration and legacy becomes fundamental. Both elements can be encountered in a number of ways. However it is manifested, legacy is a reminder of the past or other places. It is often composed through the migrations of ideas, concepts and elements that may well be reminders of the distances that the matter, or constituents forming legacy, have travelled. Legacy promotes continuity as Hegewald and Mitra state;

"Reuse contains an earlier existing element, which is taken out of its previous context and it contributes to the creation of something distinct and novel in the present. This complex item can last as it contains an important element from the past and therefore constitutes continuity and contributes to the further establishment of tradition. As such, despite containing an element of the past, re-use looks forwards and not backwards. It does not represent an end but a new beginning". 4

Because of this;

"Reuse crosses perceived...boundaries and generates items which are composite and... are perceived as being heterogeneous in their origin and composition"5

Following this logic, items that have been reused persist longer because they establish continuity and participation, and hence links to traditions, whatever they may be. As well as continuity, this is a process that will also embody a certain resistance or endurance: a durability that transcends boundaries through the act of continual reuse as opposed to the discarding and wasting of objects and environments. Hegewald and Mitra concur;

"Reuse is a conscious and selective process in which existing elements are borrowed or salvaged and taken out of their former environment in order to be applied to a new context, or they are left within their old milieu but filled with new meanings, or they get manipulated and react to new external influences. This also includes resistance to certain new elements. For this to happen, a disruption or change has to take place, favouring a confrontation with something different.... Re-use is not imitation and therefore not concerned with creating forgeries. It is a creative combination of old and new elements, which aims to re-elaborate, improve and carry further an idea, a style, an institution or a concept". 6

In summary, processes of reuse reinforce the creation of hybridity and legacy through amalgams of old and new matter. These composite constructs can be forged through adversity, can be disruptive, and enforced through significant change. Whichever events trigger change, reuse creates continuity; a direct link between the past and the present.

\section{Domesticity}

If reuse is intrinsic to the construction of the interiorscape, and if it is integral to the production of locality, how might the interiorscape spatially embody durability: and continuity? In order to exemplify the interiorscape, and its particular production through reuse, I will use the archetype of interior space: the home. Much has been written about the domestic interior and its role as the primary source of some kind of protective shelter (Bachelard 1964; Norberg-Schulz, 1984; Benjamin 1986; Rybczynski, 1987). 
In many of these publications the authors have situated the house as a composite object, a place of physical reality combined with speculative ideas. All authors have recognized that the house is both a simple, yet highly evolved complex typology of space. However it is positioned, its formal simplicity, usually consisting of a series of rooms or spaces, accentuated with furniture and objects, linked to utilities and various technologies, is described as some form of enclosure that frames the life of its occupants and the recurrent patterns of their inhabitation. In other words, because of its shelter-based attributes, the home characterizes and embodies social immediacy and refuge. It is the location of particular domestic-centred interactions through the various forms of inhabitations it embodies. Therefore, in my view, the domestic dimensions of the home, epitomizes locality, context, and site-specific based conditions for human interaction.

Descriptions of domestic spaces and their complex weave of physical and perceptual properties proliferate;

"The concept of 'Home' embraces both a physical and a social space; the house itself is a home, as are the social relations contained within it... The home thus provides an important locale within which individuals negotiate their daily lives". (Munro and Madigan, 2006)

"The house is thus a spatial imaginary: a set of intersecting and variable ideas and feelings, which are related to context, and which construct places, extend across space and scales, and connect places". (Blunt and Dowling, 2006)

While often acknowledged as the location of many complex ideas and feelings, a place where physical space conjoins with the cerebral, many writers about domestic space are drawn to describing the house as a stable entity; a protective enclosure, often positioning it as a space for nurturing the human spirit and its range of relationships:

"The original form of any mode of dwelling is that of living, not in a house, but in a shell. This bears the mark of the inhabitant. The dwelling turns into a shell" (Benjamin, 1986)

"Our house is our corner of the world...It is our first universe, a real cosmos in every sense of the word" (Bachelard, 1969)

"The density of Interior Decoration has varied, rooms have changed in size and function and have been more or less crowded with furniture, but the domestic interior has always demonstrated a feeling of intimacy and hominess" (Rybczynski, 1987)

"We may conclude that dwelling means to gather the world as a concrete building or thing, and that the archetypal act of building is the umfriedung (authors italics) or enclosure" (Norberg- Schulz, 1984)

Ranging from phenomenology to technology, to site-specificity and the temporal, the home is usually described as a concrete or fixed entity, albeit one that is sometime temporal. The utilization of reuse as a strategy for making home, could be viewed as a process that furthers a deep and substantial connection to legacy through the continuous relationship between the past and the present in order to make a shelter. As a place that incorporates the intersection of many things, including a range of variable ideas and feelings, one aspect of home is its ability to also encapsulate instability. Whilst descriptions of its nurturing and shell-like protective qualities abound, it is clear that the house is also the repository for fleeting or unstable entities such as feelings, memories and aspirations. It is as much a physical place as it is a social space, as much a solid entity as it is a temporal thing.

Therefore, how might the interiorscape of home exemplify the production of locality and offer endurance and resistance through the production of context and site-specific distinctive attributes? I suggest that through the utilization of the strategies of re-use, the domestic project can exemplify the production of locality, through their compounded or amalgamated qualities, of which their composite constructed properties are intrinsically critical to their interiorscape features.

\section{Home}

In order to exemplify the distinct qualities of the interiorscape to create space, I have chosen two particular examples of houses. Both have been impacted upon by a significant event, and which, in response, have utilized reuse to amalgamate both new and old elements of the existing site in order to produce a composite construct of a home. These new homes combine both new and old features to create sites of numerous qualities and possible meanings. These compound attributes have been achieved through the placement of new elements into the existing fabric of the buildings, in such a way as to act as reminders of the old buildings turbulent past and both of their uncertain futures.

Both the Zenkai and Hankai house projects were products of the desire to reinvent the built environment of the Japanese prefecture of Hyogo after a severe and traumatic natural disaster (Fig. 1). Both original houses were severely damaged in the 1995 Hanshin earthquake. The Hanshin-Awaji earthquake, or Kobe earthquake, resulted in the loss of 6,300 lives. One of the hardest hit areas was the cities and suburbs of the Hyogo Prefecture. One in five homes were destroyed or rendered uninhabitable by the shock, and a quarter of public buildings were damaged beyond repair. Any buildings that were constructed after 1981 mostly survived the earthquake as they were built to a new set of codes that ensured they were shock-resistant. However, those that were not constructed to those standards suffered serious structural damage or complete collapse. Many of the older traditional houses in the district had heavy tiled roofs that weighed around two tons. These were structured in order to resist the frequent typhoons that plagued Kobe and the surrounding areas. These tended to be only supported by a light timber structural frame. In the earthquake, when the wood supports gave way in the tremors, the roofs collapsed the unreinforced walls and floors and flattened the building, resulting in the loss of many lives.

\section{Zenkai house}

"I suppose that the loads will be gradually transferred to the steel framework. The wooden framework will retire from the structure, and then it will exist just as a fixture which retains the memory of the habitant's lives and the earthquake disaster" (Miyamoto, 2016)

Constructed in the 1900's, the house that Katsuhiro Miyamoto was born in was so severely damaged in the disaster that the local authorities deemed the house uninhabitable. The sentimental

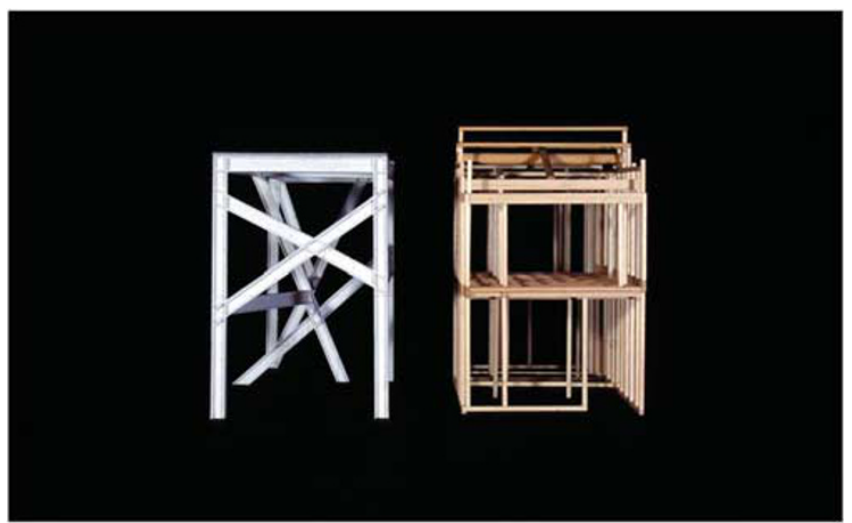

Figure 1 | Model of the Zenkai House structure. (c) Katsuhiro Miyamoto. This image is reproduced with permission of the copyright holder, and is not covered by a Creative Commons Attribution 4.0 International License. 
values that Miyamoto felt for the building, the family memories and the histories of the spaces, prompted a different response to the authorities desire to demolish and start again. The designer did not want to forget the disaster by removing all signs of the tragedy. Instead he wanted the urban environment to remember and in some way reflect this tumultuous period in its recent history. Rather than lose the character of the site and demolish the terrace of houses in which his home sat, Miyamoto proposed to intervene upon the ruin with a new structure that would impact upon the existing building in such a way as to render it a hybrid of new and old structures and appear as a monument to the recent past. The new hybrid building would also serve the pragmatic function of bringing the terrace and the house up to current earthquake resistant regulations, as well as acting as a reminder of the disaster.

Miyamoto chose to reuse and stabilize the domestic building by intervening into the existing wooden structure with a new steel frame (Fig. 2). The frame would act as a support and brace for the old timber beams and columns, ultimately taking over the role of the new structure from the existing (Fig. 3). The designer likened this process to a patient in a hospital, wrapped in a plaster cast (Zenkai) after an accident where they have broken their limbs. The frame was designed to be a support, not just for the existing building but it was also a metaphor for the healing of the house and the city after the disaster that befell it.

The new steel frame was unceremoniously placed back and in amongst the structure of the house. Then the wooden beams and columns were lashed to the new frame. The effect upon the interior ensured that the new intervention was clearly distinguished from the old, and in some places leaving the junctions between new and old brutally exposed enhanced its dynamic quality. The new structure was evident in each room, a constant reminder of the history of the city and the unfortunate disaster that befell it.

\section{Hankai house}

"The new section twines around the main building and functions as reinforcement against earthquakes (Fig. 4). The reinforcement is provided through an airy, soft wrapping" (Miyamoto, 2016)

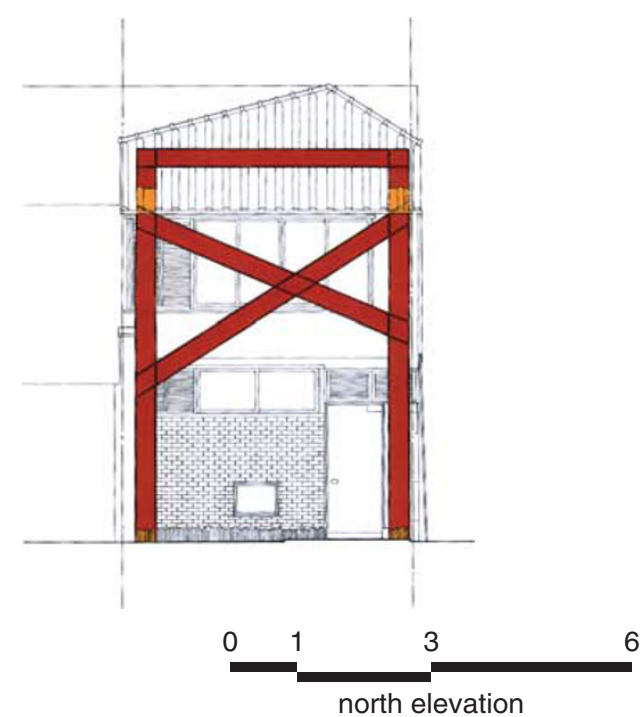

Figure 2 | Elevation of the house with the new steel frame. (c) Katsuhiro Miyamoto. This image is reproduced with permission of the copyright holder, and is not covered by a Creative Commons Attribution 4.0 International License.

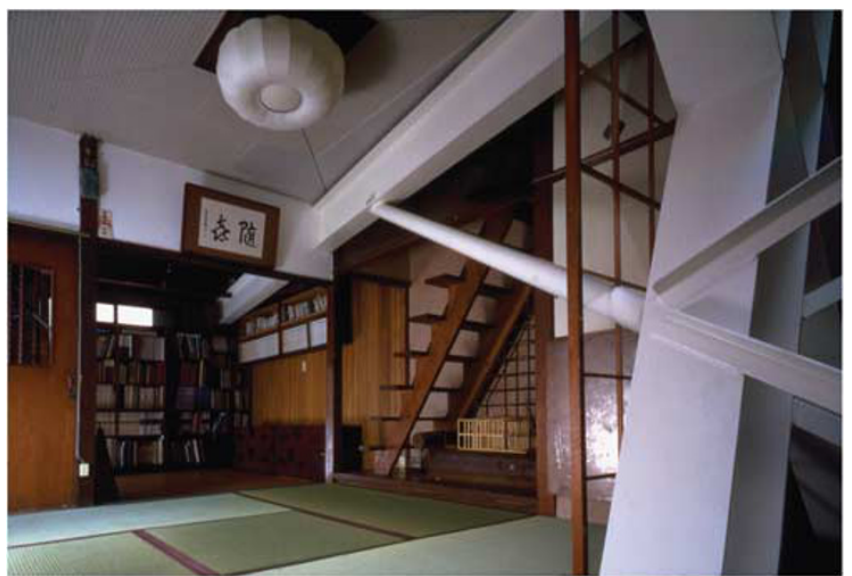

Figure 3 | The new steel frame is clearly distinguished from the old timber structure. (c) Katsuhiro Miyamoto. This image is reproduced with permission of the copyright holder, and is not covered by a Creative Commons Attribution 4.0 International License.

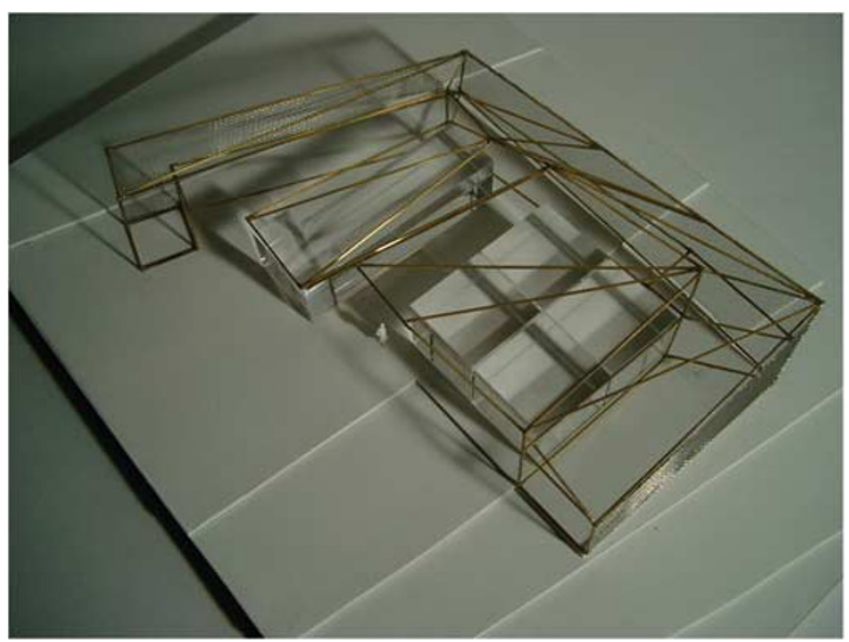

Figure 4 | Model of the House. (c) Katsuhiro Miyamoto. This image is reproduced with permission of the copyright holder, and is not covered by a Creative Commons Attribution 4.0 International License.

The Japanese word "Hankai" can be translated as "partial destruction". It was used to give the semi-demolished building a title that encapsulated its own destruction, whilst signifying its survival and a future new role after the disaster.

The existing building was a traditional three hundred year old wooden gatehouse that was partially destroyed in the earthquake. Extraneous elements that had grown up around the original square building were stripped away from the ruin in order to reinstate the original orthogonal and traditional four-room home.

In order to stabilize the house, and to ensure it would survive any future seismic activities, Miyamoto wrapped the old building with a new volume (Fig. 5). The construction acted like a "collar" 7 , or a beam that rings the old building and which reinforces and protects it from any new lateral or vertical movement. The new element contained circulation and services such as bathrooms and storage. On the top level, where it was separated from the original house, it provided a terrace and a private room. Both overlook the street below. The new wing followed the exterior boundary of the old property and created a new gatehouse, reinstating the original function of the building (Fig. 6). 


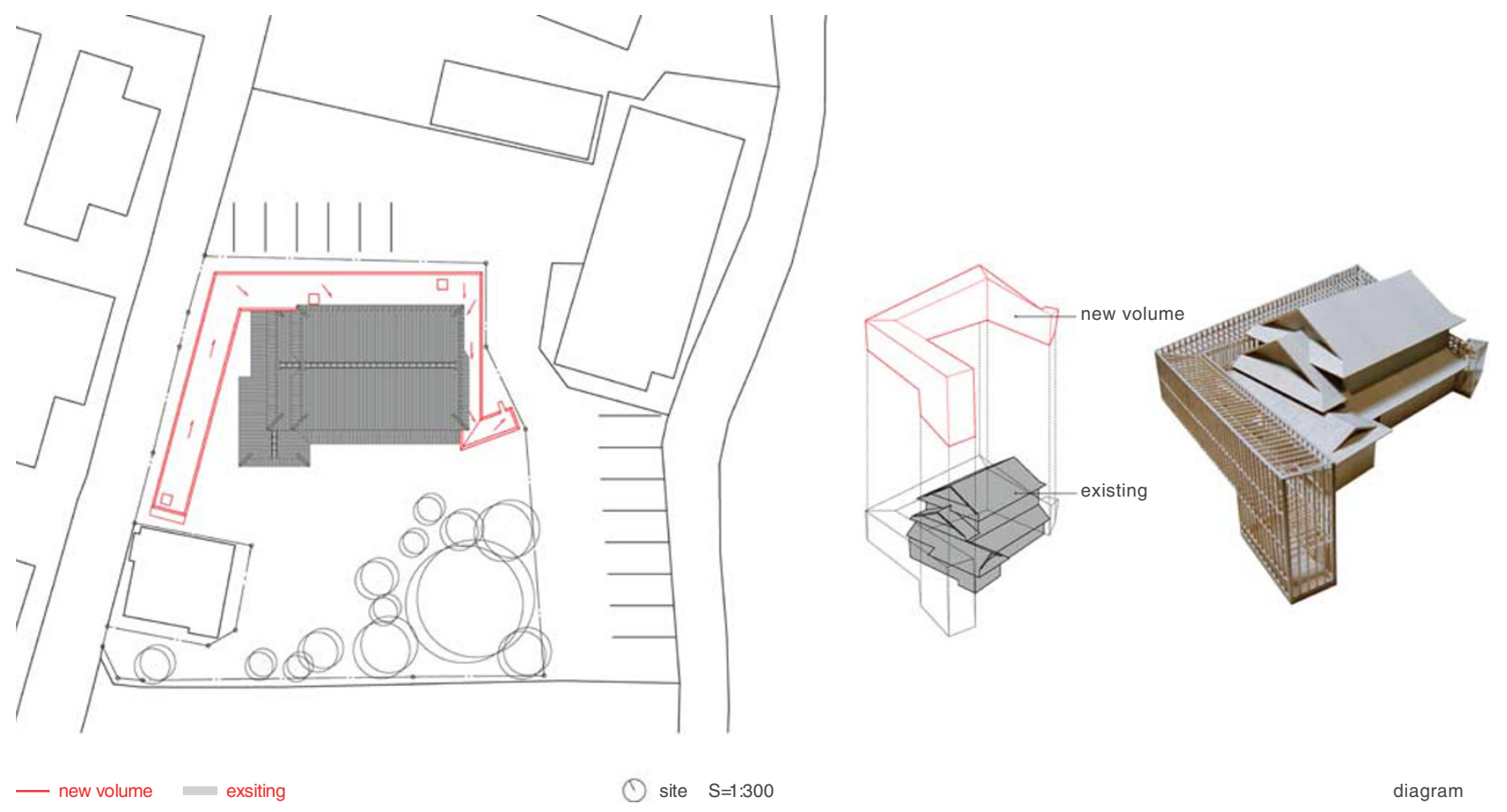

Figure 5 | The new volume was inserted around the old building. (c) Katsuhiro Miyamoto. This image is reproduced with permission of the copyright holder, and is not covered by a Creative Commons Attribution 4.0 International License.

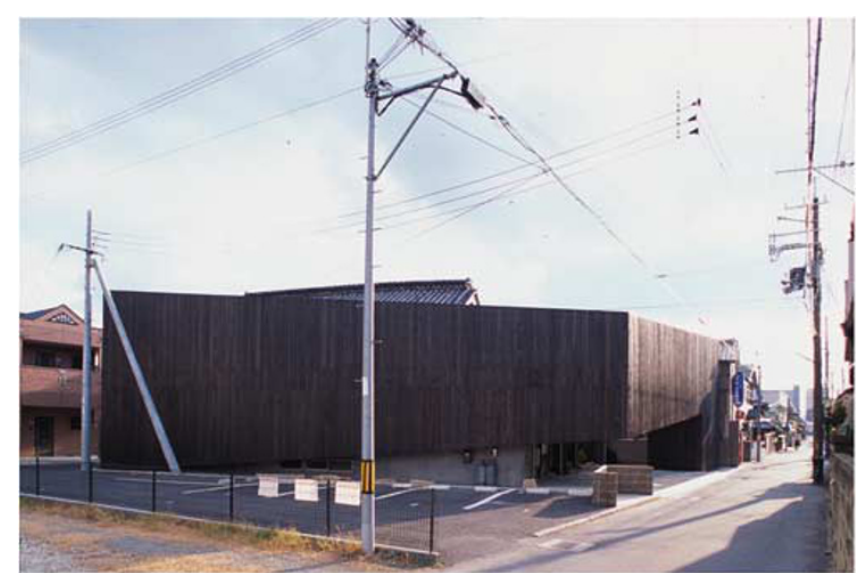

Figure 6 | Exterior of the new element. (c) Katsuhiro Miyamoto. This image is reproduced with permission of the copyright holder, and is not covered by a Creative Commons Attribution 4.0 International License.

Both houses were rendered unsafe and redundant as homes through an earthquake, but instead of being demolished, the experience inspired the designer to reuse them as new houses, and also as reminders of the past. Katsuhiro Miyamoto, the designer of both houses, remodelled them in order to be reinstated as homes, as well as to be structurally stabilised against any future seismic activities.

It is clear that these processes of remodelling the houses has created what can only be described as composite constructs, or amalgamated domestic spaces. Both homes represent interiorscapes that are both ambiguous and uncertain in their physical dimensions, and in their social relations, yet their social immediacy, through dwelling, is critical. Their technological interactivity, through restructuring and reuse, ensures that their endurance was assured and that they could once again become new homes.
Both remodelled houses contained interior spaces where the traumatic events of the past where clearly exposed and expressed in the form of, in one a robust intervention, and in the other, a severe insertion, into and around the existing buildings (Fig. 7). These changes have resulted in a set of uneasy spaces, ones where the past and its associated difficulties are clearly expressed in a robust manner. In this context, the processes of rebuilding the city, through the retention and reuse of its existing buildings and spaces, was reliant on a series of selective choices that construct an amalgam or composite of past, present, futures, all in a sitespecific manner. The retention of any existing buildings that are salvageable, allowed them to become instruments that enables both new and old to coexist in order to narrate history and chart progress, especially in a difficult or distressing context such as a natural disaster.

\section{Conclusion}

Whilst the memories of the Hanshin earthquake may fade, both houses contained the effects of the disaster in their reconstructed selves. On a deeper level, I have proposed to exemplify these two projects in order to denote the persistence of context, and also continuity. Through the reuse of both sites, Miyamoto created a legacy and endurance through the durability and persistence of objects and environments, matter that was assembled and compounded with the old to make something new. In these projects the production of a social immediacy, via domestic space, the interaction of technologies, both natural and artificial, such as composite construction as well as the earthquake, have manufactured a distinct locality and two very unique sitespecific spaces.

In the two domestic spaces designed by Miyamoto, the interiorscape is exemplified as a fluid and dynamic terrain, an environment created through the use of particular strategies and activities, predominantly based upon processes of reuse. They are approaches that are utilized in order to produce what Arjun Appadurai describes as localities: 


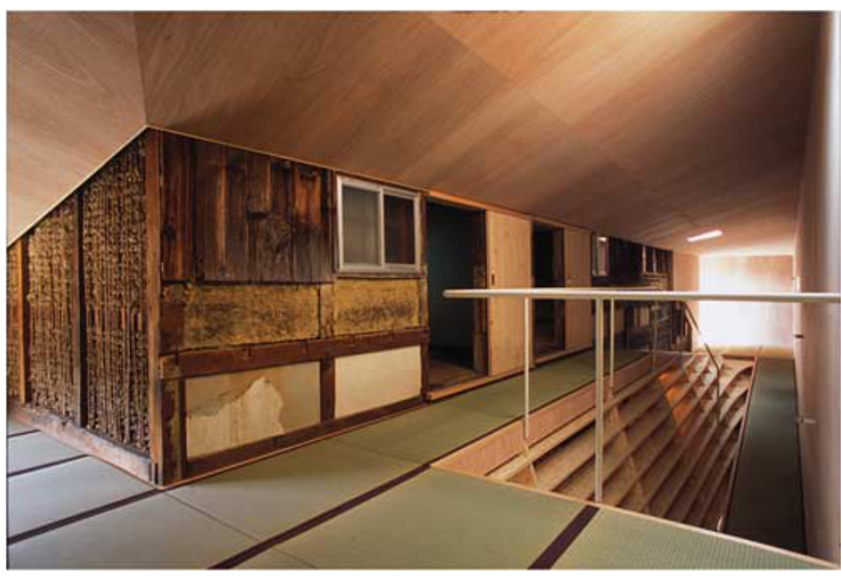

Figure 7 | The interior space where the old house is stabilised by the new insertion. (c) Katsuhiro Miyamoto. This image is reproduced with permission of the copyright holder, and is not covered by a Creative Commons Attribution 4.0 International License.

"I see (locality) as a complex phenomenological quality, constituted by a series of links between the sense of social immediacy, the technologies of interactivity, and the relativity of contexts" (Appadurai, 1996).

Appadurai devised five scapes in an attempt to simplify what he saw as an intensely complex set of relationships. Ethno, Techno, Ideo, Media and Finance-scapes were entities that created connections that set the basis for the conditions around which global flows and interactions of people, money, images, and narratives, occurred.

His employment of these themes to describe flows of cultural and political ideas and material resulted in conditions that he acknowledged can be volatile, chaotic, dynamically unpredictable and ultimately disjunctive. In order to try to make sense of these factors, and to try to possibly counter, or understand, the resultant deterritorialization, he countered the unpredictability and fluid dynamic of this terrain by proposing a counter argument, one where he hypothesized that:

"...The relationship of these various flows to one another as they constellate into particular events and social forms will be radically context-dependent" 8

Essentially, in context to the five scapes, Appadurai used the term locality to describe the production of relational and contextual matter. As he suggested;

"This phenomenological quality, which expresses itself in certain kinds of agency, sociality and reproducibility, is the main predicate of locality". 9

Appadurai spatialised locality as a tool to offer possible resistances to what he perceived as the increasingly destabilizing effect of the dynamic flow, and ultimately liquidity, of each of the five scapes. He described it as a social form that could be viewed as the production of a space of resistance to intense deterritorialization and the fluidity of global interactions. I use Appadurai's work in order to emphasize the fluidity of the five scapes and the counterpoint of locality in order to distinguish the interiorscape as the site of an intense spatial condition that describes a persistent tendency in the production of locality, and thus affirming the qualities of site-specificity, and hence reinforcing particular relations between a site, a building, a place, and a community. In the case of Zenkai and Hankai houses, because of the devastating event, site-specific resistance to complete eradication and change through demolition was achieved through the amalgamation and composition of old and new elements and forms through reuse to make the new homes.

Advancing Appadurai's work, I would add that the production of locality is an integral aspect of the interiorscape. It relies on the logic of constructed social and spatial relationships between people, space and terrain. All localities, and by extension interiorscapes, have a moment of colonization through the assertion of some form of space, group, habitation, occupation and neighbourhood. As Appadurai suggested;

"neighbourhoods are contexts in the sense that they provide the setting within which various kinds of human interaction... can be initiated and conducted meaningfully". ${ }^{10}$

I propose that neighbourhood could easily be substituted with interiorscape; a multiplex set of interpretive contexts that constitute a multiplicity of concepts, forms of occupation, and meaningful interactions in space. One of the attributes of interior space is that it is the principal enclosure of human interaction and inhabitation. Whether home, work, leisure or knowledge based forms of occupation, the interior is undoubtedly a critical space, central to all forms of inhabitation. In order to substantiate the interiorscape and its role as an Appadurai neighbourhood, the role of reuse as a strategy for making interior environments ensures that site-specificity is intrinsic to the formation of the space and is achieved through the incorporation of existing and found matter. This is evident in both the Zenkai and Hankai Houses.

On the basis of this understanding of site-specific reuse and integrative processes, developed repeatedly through "disruptive" or confrontational approaches, I propose that the Interiorscape, is the origination and assembly of what I describe as a space that is an amalgam or a composite construct. This renders the interiorscape as an environment that, because it is usually conceptualized and constructed from many different existing ideas and elements, many of which are often originated from numerous diverse locations and from differing timescales of production, it can be described as a compound: a space that is the result of the combination or mix of several distinctive entities. All of these elements are amalgamated together in order to forge new spatial meanings - a composite of both new and old. Miyamoto's houses are both composite constructs, amalgams of both new and old elements assembled for very particular reasons.

This is one of the fundamental principles or founding constructs of the interiorscape. As a result of this approach, the subsequent amalgam or composite construct, critical to the origination and formation of the interiorscape, encapsulates the production of a context-based locality. On this basis it is conceivable that the interiorscape can be understood as a place of endurance, and, due to its distinctive location driven attributes, it is a site of a spatial dynamic: one that is in contrast to the liquid and highly mobile forms of globalized scapes that Appadurai foregrounds.

\section{Notes}
1 ibid p 538
2 ibid p 1800
3 ibid $\mathrm{p} 31$
4 ibid.p 43
5 ibid. p 47
6 ibid. p 49
7 "Collar" is used to describe a structural device surrounding and holding something in place.
8 ibid p 47-my italics.
9 ibid $\mathrm{p} 178$.
10 ibid $\mathrm{p} 184$ 


\section{References}

Adams RE (2017) Towards a theory of interior. In: Stoppani T et al. (eds). This Thing Called Theory. Routledge: Oxford, $\mathrm{p} 243$.

Appadurai A (1996) Modernity at Large, Cultural Dimensions of Globalization. Public Works University of Minnesota: Minnesota, p 178.

Bachelard G (1964) The Poetics of Space. Beacon Books: Boston, MA.

Bachelard G (1969) The Poetics of Space. Beacon Books: Boston, MA, p 4.

Barnard N (2012) Indian jewellery and nineteenth century Britain: Evolving patterns of re-use. In: Hegewald JAB and Mitra SK (eds). RE-USE: The Art and Politics of Integration and Anxiety. Sage Publications: India, $\mathrm{p} 107$.

Barnhart RK (1988a) Chambers Dictionary of Etymology Chambers. Harrap: Edinburgh, UK, p 538.

Barnhart RK (1988b) Chambers Dictionary of Etymology Chambers. Harrap: Edinburgh, UK, p 342.

Benjamin W (1986) Das Passagenwerk. Tiedermann R (ed). Suhrkamp Verlag: Frankfurt, Germany, p 9.

Blunt A and Dowling R (2006) Home. Routledge, Taylor and Francis: London, $\mathrm{p} 2$.

Hegewald JAB and Mitra SK (2012a) RE-USE: The Art and Politics of Integration and Anxiety. Sage Publications: India, p 3.

Hegewald JAB and Mitra SK (2012b) RE-USE: The Art and Politics of Integration and Anxiety. Sage Publications: India, $\mathrm{p} 32$.

Miyamoto K (2016) Interview with author in Takarazuka, in the house/studio, Japan.

Munro M and Madigan R (2006) Negotiating space in the family home. In: Cieraad I (ed). At Home: Anthropology of Domestic Space. Syracuse University Press: Syracuse, NY, p 107.

Norberg-Schulz C (1984) Genius Loci: Towards a Phenomenology of Architecture. Rizzoli: New York, p 217.

Onions CT (1972) The Shorter Oxford English Dictionary: On Historical Principles. Oxford University Press: Oxford, p 1800.

Rice C (2007) The Emergence of the Interior. Architecture, Modernity, Domesticity. Routledge: Oxford, p 10.
Rybczynski W (1987) Home: A Short History of an Idea. Penguin Books: London.

\section{Data availability}

Data sharing is not applicable to this article as no datasets were analysed or generated.

\section{Acknowledgements}

The author would like to acknowledge and thank the DAIWA foundation scholarship for supporting a trip to Japan to interview Katsuhiro Miyamoto in the summer of 2016 in the Zenkai house/studio.

\section{Additional information}

Competing interests: The author declares no competing financial interests.

Reprints and permission information is available at http://www.palgrave-journals.com/ pal/authors/rights_and_permissions.html

How to cite this article: Brooker G (2017) The interiorscape: amalgams and composites Palgrave Communications. 3:17057 doi: 10.1057/palcomms.2017.57.

Publisher's note: Springer Nature remains neutral with regard to jurisdictional claims in published maps and institutional affiliations.

\section{(c) (i)}

This work is licensed under a Creative Commons Attribution 4.0 International License. The images or other third party material in this article are included in the article's Creative Commons license, unless indicated otherwise in the credit line; if the material is not included under the Creative Commons license, users will need to obtain permission from the license holder to reproduce the material. To view a copy of this license, visit http://creativecommons.org/licenses/by/4.0/

C) The Author(s) 2017 